\title{
Tumor de células granulares de próstata diagnosticado en biopsia transrectal. ¿Qué actitud tomar?
}

\author{
Pérez Valcárcel J*, Sánchez Arca ME*, Sousa Escandón A**, Uribarri González CV** \\ *Servicio de Patología. **Servicio de Urología. Hospital Comarcal de Monforte. Monforte de Lemos. Lugo.
}

Actas Urol Esp. 2006;30(10):1031-1033

\section{RESUMEN}

TUMOR DE CÉLULAS GRANULARES DE PRÓSTATA DIAGNOSTICADO EN BIOPSIA TRANSRECTAL. ¿QUÉ ACTITUD TOMAR?

El tumor de células granulares (TCG) es una neoplasia de derivación neural, relativamente frecuente en localización subcutánea y en cavidad oral. En próstata es excepcional, con un solo caso descrito en la literatura indexada de las últimas tres décadas. Presentamos el caso de un varón de 63 años con clínica de prostatismo, próstata aumentada de tamaño e incremento de cifras de PSA sérico, al que en biopsia transrectal por aguja se le diagnostica TCG. Dada la excepcionalidad de la neoplasia no existe un protocolo de actuación establecido. Planteamos el dilema clínicopatológico que representa el diagnóstico de una neoplasia de estas características y proponemos la actitud más adecuada a seguir.

Palabras clave: Tumor de células granulares. Próstata. Biopsia transrectal por aguja. Seguimiento.

\section{ABSTRACT \\ GRANULAR CELL TUMOUR OF PROSTATE DIAGNOSED BY TRANSRECTAL BIOPSY. WHICH THERAPEUTIC ATTITUDE?}

Granular cell tumour (GCT) is not an uncommon tumour of neural origin usually located on subcutaneous tissues and oral cavity. In prostate gland is exceptional, with only one case reported on the indexed literature of the last three decades. We report a case of a 63-year-old man presented with urinary complaints, enlarged prostate and increased PSA levels. The patient subsequently underwent transrectal needle biopsy which revealed GCT. The clinicpathological dilemma originated after this diagnosis is discused and the most suitable follow-up is proposed.

Keywords: Granular cell tumour. Prostate. Transrectal needle biopsy. Follow-up.

El tumor de células granulares (TCG) es una neoplasia no infrecuente de derivación neural que surge generalmente en tejidos blandos subcutáneos o en cavidad oral ${ }^{1-3}$. Su curso es benigno en la inmensa mayoría de los casos, con curación tras resección quirúrgica y un índice de recidivas bajo ${ }^{1,4}$. Sin embargo en localización visceral y en concreto en territorio urológico es una neoplasia rara ${ }^{5}$; en próstata es excepcional, con un solo caso descrito en la literatura indexada de las últimas tres décadas ${ }^{6}$.

\section{CASO CLÍNICo}

Varón de 63 años con antecedentes de prostatismo moderado y un episodio aislado de retención aguda de orina. El tacto rectal evidencia adenoma II/IV liso con crecimiento intrarrectal y con ecografía se observa una próstata homogénea aumentada de tamaño. El PSA inicial es de 8,09 (Índice PSA libre: 0,13), y en un control realizado a los 4 meses es de 8,56 (Índice PSA libre: $0,16)$, por lo que se realiza biopsia transrectal por aguja. 
Se remiten a nuestro laboratorio nueve cilindros de tejido procedentes de biopsia transrectal de lóbulos derecho e izquierdo prostático. Las secciones histológicas fueron teñidas con hematoxilina-eosina. Se realizaron además técnicas de inmunohistoquímica sobre secciones de parafina mediante técnica de estreptavidinabiotina (kit LASB 2 Sustem-HRP; Dako) tras desenmascaramiento antigénico con tampón citrato en olla a presión. Se utilizaron los siguientes anticuerpos: Citoqueratinas AE1AE3 (Prediluido, Dako); S-100 (Policlonal, prediluido, Dako) y CD68 (Clon PG-M1, concentración 1:50, Dako).

En el material de biopsia se observa en uno de los fragmentos procedentes del lóbulo izquierdo infiltración por una neoplasia difusa de células de núcleo pequeño, no atípico, y citoplasmas muy amplios y granulares (Fig. 1). Los gránulos en ocasiones forman pequeños acúmulos redondeados, y son PAS positivos. Con técnicas de inmunohistoquímica la celularidad neoplásica es negativa para citoqueratinas y fuertemente positiva para CD-68 y S-100 (Fig. 2). Con todo ello fue etiquetado como tumor de células granulares. En el resto de los fragmentos de ambos lóbulos se apreciaron cambios de hiperplasia, sin que se evidenciara neoplasia maligna.

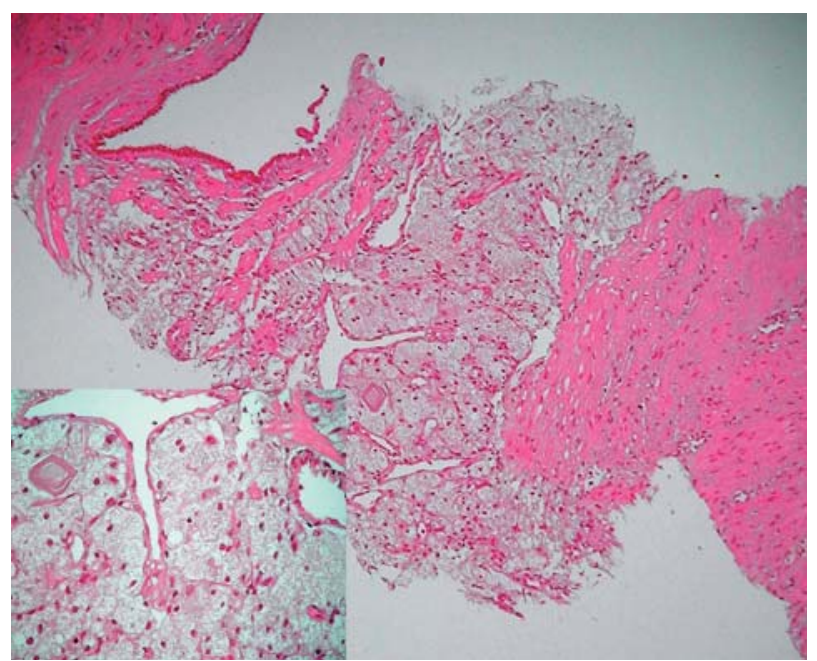

FIGURA 1. Panorámica de la tumoración, mostrando infiltración difusa del tejido prostático por TCG (H-E, $x$ 40). En el recuadro (H-E, $x$ 400) se aprecia el caracteristico aspecto granular del citoplasma y la ausencia de atipia.

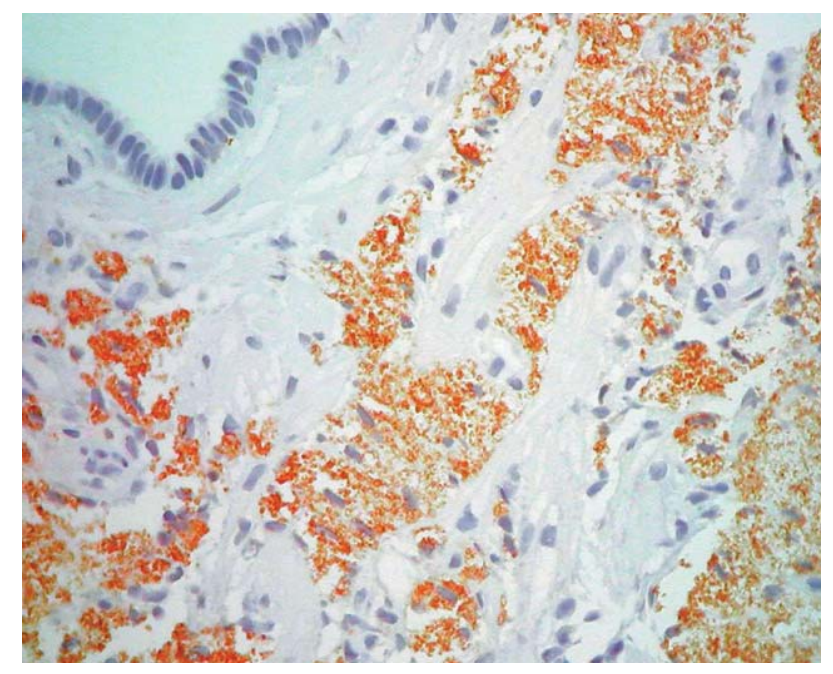

FIGURA 2. Inmunotinción citoplasmática intensa de las células neoplásicas para S-100 (Estreptavidina-biotina, $x$ 100).

\section{DISCUSIŌN}

Más allá de la excepcionalidad del caso desde el punto de vista patológico, desde el urológico deja todos los interrogantes abiertos:

- ¿Caso resuelto?: Aunque podría ser que sí, la prudencia dicta que no. Si bien la presencia de un TCG podría explicar las cifras elevadas de $\mathrm{PSA}^{8}$, la posibilidad de neoplasia maligna concomitante no puede ser excluida, aún en ausencia de malignidad en el resto de fragmentos. Lo prudente y necesario es el seguimiento del paciente.

- ¿Maligno o benigno?: En función de los hallazgos en el material de biopsia la neoplasia es benigna. Sin embargo es necesario tener en cuenta dos consideraciones: la primera es que existe el TCG maligno que, aunque muy raro ${ }^{1,9}$, ha sido descrito en territorio urológico ${ }^{7,10}$; la segunda es que no siempre es posible establecer el diagnóstico de malignidad o benignidad sobre criterios histológicos ${ }^{1,9}$, y menos en el caso de una muestra con las pequeñas dimensiones de una biopsia por aguja, ya que los cambios diagnósticos de neoplasia maligna pueden ser parciales dentro del tumor $^{1}$. Para añadir un punto más de incertidumbre al problema es necesario señalar que en algunos casos de TCG maligno ha sido observada una historia de larga evolución seguida por una fase de crecimiento rápido, sugiriendo así la posibilidad de transformación maligna de un TCG benigno preexistente, de una forma análoga a la transformación maligna del neurofibroma ${ }^{1}$. 
- ¿Qué actitud tomar? Teniendo en cuenta todo lo anterior y que, dada la excepcionalidad de la neoplasia, no existe un protocolo de actuación establecido $^{11}$, la actitud más adecuada sería un seguimiento clínico conservador, controlando periódicamente las cifras de PSA, y dejando abierta la posibilidad de realizar una RTU prostática si la evolución clínica lo requiriese.

El objetivo principal de las biopsias tumorales es la correcta tipificación diagnóstica de las neoplasias, lo cual permitirá realizar un tratamiento adecuado de las mismas. Sin embargo, existen situaciones concretas que parecen contradecir este esquema universalmente aceptado, de forma que un diagnóstico correcto, lejos de favorecer el manejo de un paciente, paradójicamente puede llegar a complicarlo. El caso que presentamos es ilustrativo de esta situación. Esta lesión, al igual que ocurre con los PIN de alto grado, las atrofias parcheadas, las hiperplasias atípicas y otras lesiones acinares prostáticas, genera más dudas que respuestas, y obliga a un enfoque y seguimiento individualizado. El diálogo fluido entre urólogo y patólogo es, más que nunca, imprescindible para que éstos sean los más adecuados en cada caso.

\section{Agradecimientos}

A Coral Varela Fraga y Patricia Vázquez Enríquez, TEAP del Servicio de Patología de nuestro centro, por su colaboración en los aspectos técnicos de este trabajo.

\section{REFERENCIAS}

1. Weiss SW \& Goldblum JR. Enzinger and Weiss's Soft Tissue Tumors. Fourth edition. Mosby. 2001;1622.

2. Rosai J. Rosai and Ackerman's Surgical Pthology. Ninth edition. Vol. 2. Mosby, 2004;1483-2977.

3. Qureshi NA, Tahir M, Carmichael AR. Granular cell tumour of the soft tissues: a case report and literature review . Int Semin Surg Oncol. 2006 Aug;24(3):21.

4. Strong EW, McDivitt RW, Brasfield RD. Granular cell myoblastoma. Cancer. 1970;25(2):415-422.

5. Kondo T, Kajimoto S, Okuda H, Toma H, Tanabe K. A case of granular cell tumor of the bladder successfully managed with extraperitoneal laparoscopic surgery.Int J Urol. 2006 Jun;13 (6):827-828.

6. Furihata M., Sonobe H, Iwata J, Ido E, Ohtsuki,Y, Kuwahara $\mathrm{M}$ et al. Granular cell tumor expressing myogenic markers in the prostate. Pathology International. 1996;46(4):298-300.

7. Zhuang YZ, Jiang XY, Chen PQ. Malignant granular cell tumor of the urinary bladder. Zhonghua Bing Li Xue Za Zhi. 2006 Mar;35(3):188.

8. Humphrey PA, Vollmer, RT. Relationships between serum prostate-specific antigen and histopathologic appearances of prostate carcinoma. In Foster CS \& Bostwick DG. Pathology of the Prostate. Major Problems in Pathology. 34. WB Saunders Company, 1998;253-281.

9. Wang J, Zhu XZ, Zhang RY. Malignant granular cell tumor: a clinicopathologic analysis of 10 cases with review of literature. Zhonghua Bing Li Xue Za Zhi. 2004 Dec;33(6):497-502.

10. Ravich A, Stout AP, Ravich RA. Malignant granular cell myoblastoma involving the urinary bladder. Ann Surg. 1945;121: 361.

11. Mnasri H, Bouchoucha S. Granular cell tumour of the perianal region: which therapeutic attitude? Acta Chir Belg. 2005 Feb;105(1):112-113.

Dr. J. Pérez Valcárcel

E-mail: javier.perez.valcarcel@sergas.es

(Trabajo recibido el 1 de septiembre 2006) 